\title{
The Cost of Impression Management to Life Satisfaction: Sense of Control and Loneliness as Mediators
}

\author{
Wangshuai Wang' \\ Ke Zhou ${ }^{2}$ \\ Zucheng $\mathrm{Yu}^{3}$ \\ Jie $\mathrm{Li}^{4}$
}

'School of Management, Shanghai University of International Business and Economics, Shanghai, People's Republic of China; ${ }^{2}$ Antai College of Economics and Management, Shanghai Jiao Tong University, Shanghai, People's Republic of China; ${ }^{3}$ School of International Relations and Public Affairs, Shanghai International Studies University, Shanghai, People's Republic of China; ${ }^{4}$ School of Management, Shanghai University, Shanghai, People's Republic of China
Correspondence: Zucheng Yu

School of International Relations and

Public Affairs, Shanghai International

Studies University, Shanghai, People's

Republic of China

Email enxiawws@gmail.com
This article was published in the following Dove Press journal: Psychology Research and Behavior Management

Purpose: Impression management, or self-presentation, prevails in our daily lives. However, whether it enhances or reduces individuals' well-being remains underexplored. To fill this gap, the research proposed and tested the following hypotheses. Impression management is negatively related to life satisfaction. Impression management is negatively related to sense of control. Impression management is positively related to loneliness. Sense of control and loneliness mediate the relationship between impression management and life satisfaction.

Methods: Data were collected from an online survey of 243 Chinese adults drawn from a national sampling frame. We used LISREL8.8 to perform a series of CFAs to verify the distinctiveness of variables and conducted SEM modeling to test hypotheses. To further test the mediation hypotheses, we used bootstrapping procedures that generated a sample size of 5000.

Results: We found a negative association between impression management and life satisfaction. In addition, the association was fully mediated by sense of control and loneliness.

Conclusion: These results reveal that impression management is a negative indicator of life satisfaction because impression management impedes personal sense of control and elevates loneliness.

Keywords: impression management, sense of control, loneliness, life satisfaction

\section{Introduction}

Impression management is the process by which people manage the impressions that others form of them. ${ }^{1}$ The impression that one gives to other people plays a pivotal role in determining how they are perceived and evaluated by others. Therefore, some people pay particularly strong attention to maintain a positive public image in order to avoid negative evaluations against them. ${ }^{1,2}$

A body of literature has focused on impression management, given its important role in social life. The importance of impression management is well documented in different research areas, such as interpersonal relationships, ${ }^{3}$ conformity, ${ }^{4}$ and job performance appraisal. ${ }^{5}$ Another stream of research identifies the antecedents of impression management. It is believed that one's public self-consciousness, which is defined as a person's awareness of the presence of an audience, boosts impression management motive. ${ }^{6,7}$ Similarly, self-monitoring reflects social appropriatenessdirected self-observation, hence it is positively related with impression management. ${ }^{8}$ 
Recent research has delved into the behavioral consequences of impression management. Mixed evidence has been found that both benefits and risks can be brought by impression management. ${ }^{9,10}$ However, these studies do not explore the possible impact of impression management on subjective well-being. In particular, it is unclear in the literature how impression management influences life satisfaction. On one hand, individuals who manage their impressions can enjoy and benefit from possessing a positive social image. ${ }^{11-13}$ On the other hand, they also have to expend much effort in this process, which may be laborious and stressful. In some cases, impression management may even backfire and be harmful, such that individuals who aim to be regarded as friendly or capable through impression management turn out to be taken as flatterers or boasters, respectively. ${ }^{14,15}$

To fill this gap, we investigate the effect of impression management on life satisfaction, which serves as a central component of subjective well-being. ${ }^{16}$ We also discuss the underlying mechanism accounting for this effect. Specifically, we test how impression management affects sense of control and loneliness, which in turn influence life satisfaction.

\section{Literature Review and Hypothesis Development}

\section{Impression Management and Life Satisfaction}

Impression management has been discussed in the literature for several decades. Researchers have identified some factors that influence impression management. For example, Berinsky ${ }^{17}$ finds that demographic variables including gender and age are associated with individuals' impression management; specifically, the result from a random-digitdial survey of 518 Americans indicated that females and those older in age scored higher on the impression management scale. Alexander and Knight ${ }^{18}$ propose that social interactions require self-monitoring, which in turn facilitates impression management behavior. Furthermore, selfmonitoring not only promotes impression management generally, but also affects the specific strategies people use when managing their impressions. ${ }^{10,19}$

More recently, the behavioral consequences of impression management have drawn the increasing attention of researchers in various fields. Krämer and Winter ${ }^{20}$ propose that impression management is an important motive for those who actively participate in social networking sites (SNS); such that SNS users' self-efficacy pertaining to impression management is positively related to the number of virtual friends they have. Impression management is also influential for consumers, who intentionally balance their shopping basket compositions in order to maintain positive impressions. ${ }^{21}$ In an organizational context, Liu, Wang, and Wayne $^{22}$ investigate how employees' impression management and learning goal orientation jointly affect their creativity and mentors' provision of mentoring functions.

There is little empirical evidence showing that impression management is negatively associated with life satisfaction. Nonetheless, some existing research has shed an initial light on this relationship. For instance, impression management is found to be negatively associated with a supervisor's evaluation of job performance, ${ }^{23}$ which is a key predictor of job and life satisfaction of subordinates. ${ }^{24}$ Similarly, Impression managers fear of negative evaluations that spoil social image, and such fear has a negative impact on psychological well-being. ${ }^{25}$ Furthermore, Leary, Tchividijian, and Kraxberger ${ }^{26}$ argue that people are more likely to be under psychological pressure if they are concerned too much with what others think of them, which can even increase health risks related to cancer, HIV, and substance abuse. With the increasing popularity of social media, more impression managers have switched to the online battlefield where they can build and maintain their social images without the limit of time and space. ${ }^{27}$ For example, they post genuine or nongenuine posts and selectively display advantageous personal profiles to manage their desired impressions. ${ }^{28,29}$ Some papers indicate the strengths of online impression management, such as convenience. ${ }^{30}$ However, a larger body of research points out the negative consequences of impression management through social media, such that it is closely linked to mental health problems. For instance, Jang, Park, and Song ${ }^{31}$ find that impression managers on social media are more likely to engage in upward social comparison, which is harmful to mental health. Similarly, online impression management is shown to be related to depressive symptoms. This effect is more pronounced among females. ${ }^{32}$ Berryman, Ferguson, and $\mathrm{Negy}^{33}$ show that impression management on social media is tied to decreased empathy and even suicidality. Moreover, poor mental health is associated with low satisfaction with life. ${ }^{34}$ Consistent with this line of research, we hypothesize that impression management damages life satisfaction.

H1: Impression management is negatively related to life satisfaction. 


\section{Impression Management, Sense of Control, and Loneliness}

Sense of control, also known as perceived control, refers to the subjective expectations about one's ability to exert influence over life circumstances and outcomes. ${ }^{35} \mathrm{We}$ propose that impression management undermines one's sense of control. The reason is that the process of managing impressions is filled with difficulties, uncertainties, and even risks, which in turn undermine perceived control. ${ }^{35}$ First, impression management is difficult. For example, for employees who are not politically skilled, the more impression management work they conduct, the more undesirable social images they make in their supervisors' eyes. ${ }^{23}$ Second, impression management is full of uncertainties. This is because people have contrasting standards in evaluating what is good or bad. It is usual that certain behavior in line with the norm in one's view is regarded as inappropriate by others. ${ }^{36}$ As a result, people in most cases are unable to know whether they have effectively built positive images even after expending considerable effort, as the results are completely determined by others. Third, impression management is risky. Research indicates that impression management is usually associated with deception and faking behavior, ${ }^{37-39}$ which embed the risk of being exposed. People who engage in impression management are aware that if others notice their deception or faking behavior, impression management work will backfire and their social images can be even worse. ${ }^{25}$ Therefore, even if impression management is successful in the short term, one is still concerned about how long the ideal result can last.

Furthermore, impression management can make people feel lonely. We draw on theory of social support to justify this notion. According to this theory, social support serves as a type of social resources supplied by one's networks. Providing social support is considered as prosocial because the providers do not take this action as a deal and thus seek for no exchange in this social interaction. ${ }^{40,41}$ As a result, people tend to offer social support to others who are in need. For example, when natural disasters happen (e.g., earthquakes, droughts, and floods), many individuals volunteer to provide timely and various kinds of support (e.g., emotional, informational, and tangible support) for the people in trouble. ${ }^{42,43}$ They help the refugees selflessly because they notice that the refugees suffer from severe losses and are thus in great need for help. However, individuals who manage their social impressions are unwilling to show their hardships and struggles to others. In reverse, impression managers tend to display positive social images (e.g., high competence, resource abundance) to create more desirable impressions. ${ }^{9,44}$ Therefore, their friends and colleges are less likely to give them support as they observe little need. Moreover, a large body of research has indicated that the decreased social support leads to increased loneliness. ${ }^{45-47}$ Taken together, these findings jointly support the positive relationship between impression management and loneliness. Therefore, we propose the following hypothesis.

H2a: Impression management is negatively related to sense of control.

H2b: Impression management is positively related to loneliness.

\section{The Mediating Role of Sense of Control and Loneliness}

The above analyses have discussed the influence of impression management on sense of control and loneliness. To further address the mediating effect, we need to identify the relationship between sense of control, loneliness, and life satisfaction.

A high sense of control means a great deal of command and little-perceived constraints. ${ }^{48}$ People have a general need for personal control, thereby striving to restore control when it is threatened or lost. ${ }^{49}$ Because sense of control is indispensable in daily life, it is no surprise that its positive relationship with life satisfaction has received convergent support in different studies. ${ }^{48,50,51}$

In contrast, loneliness is an aversive state characterized by pessimism and depression. ${ }^{52,53}$ This is because humans are social animals, and they have a fundamental need to seek and maintain relationships with others. ${ }^{54,55}$ If social connectedness is absent (for example, when being socially excluded), one will suffer from loneliness. Loneliness causes a series of negative consequences. It triggers negative emotions, including anxiety and depression. ${ }^{56}$ Loneliness has also been found to be associated with decreased self-esteem. ${ }^{57}$ Moreover, lonely people's social behavior can be distorted. Research indicates that people suffering from loneliness have social skills deficits ${ }^{58}$ and improper patterns of self-disclosure. ${ }^{59}$ The aversion of loneliness is also self-evident by the compensatory or reactance responses that people adopt to cope with it, such as impulsive consumption, ${ }^{60}$ decreased prosocial 
behavior, ${ }^{61}$ and increased self-defeating behavior. $^{62}$ Therefore, we propose the following hypothesis:

H3a: Sense of control mediates the relationship between impression management and life satisfaction.

H3b: Loneliness mediates the relationship between impression management and life satisfaction.

\section{Data and Method}

\section{Participants and Procedures}

We collected original data from an online survey including 243 Chinese adults. More specifically, the participants were recruited in mainland China using Sojump (http:// www.sojump.com), which is a professional online survey platform similar to Amazon's Mechanical Turk. Sojump has a large, diverse workforce that consists of over 2.6 million users. A large stream of previous psychological research has shown that the crowdsourcing services provided by Sojump are reliable. ${ }^{63,64}$ Before the survey, we showed the participants a cover letter that explained the objectives of this research and guaranteed anonymity. Then the participants completed the items the authors presented. After completion, they were thanked for their participation and given a monetary payment (3 yuan). In our sample, 195 respondents $(61.7 \%)$ and 121 respondents (38.3\%) were female and male, respectively. Two hundred and forty-nine respondents (79.8\%) were aged between 18 and 35 years old. Two hundred and seventy-nine respondents' $(89.5 \%)$ monthly income ranged from 2000 to 6000 yuan. In terms of education, $98.7 \%$ of the participants had a college degree or higher. Also, $97.5 \%$ of them had been employed by their company for no less than 4 years. To support disclosure and replication in research, the data and syntax are available at pan.baidu.com/s/1bmrdoWIpjN fJVP5qeP_xow (code: c3bm).

\section{Ethics Approval and Informed Consent}

This study was approved by the research ethics board of the Shanghai University of International Business and Economics. All procedures in the present research involving human participants were in accordance with the ethical standards of the institutional research committee and with the 1964 Declaration of Helsinki and its later amendments. Written informed consent was obtained from all participants included in the study.

\section{Measures of Constructs}

Impression Management

We assessed impression management by adapting the Marlowe-Crowne Form A scale with eleven items $(\alpha=$ 0.76 ) in a true/false format, ${ }^{65}$ which is one of the most commonly used scales in measuring impression management, ${ }^{66,67}$ and is shown to fit better than the original scale. ${ }^{68}$ A sample item is "To maintain the positive social image, I'm unwilling to admit it in public when I make a mistake."

\section{Sense of Control}

We used 12 items adapted from Lachman and Weaver ${ }^{48}$ to create this measure $(\alpha=0.82)$. Participants were asked to indicate the extent to which each of the statements described them using a seven-point scale $(1=$ strongly disagree; 7 = strongly agree). Sample items are "When I really want to do something, I usually find a way to succeed at it" and "I often feel helpless in dealing with the problems of life".

\section{Loneliness}

We used Russell's ${ }^{69}$ UCLA Loneliness Scale to assess participants' loneliness $(\alpha=0.89)$. This scale is widely used and has well-established reliability and validity in different contexts. On a four-point scale ranging from 1 , "never," to 4, "always," participants rated how often they felt the way described. Sample items are "How often do you feel that you lack companionship" and "How often do you feel that there is no one you can turn to".

\section{Life Satisfaction}

Life satisfaction was measured using a scale developed by Diener et $\mathrm{al}^{16}$ On a seven-point scale $(1=$ strongly disagree; $7=$ strongly agree), participants indicated their agreement with each item. Items include "In most ways my life is close to my ideal," and "The conditions of my life are excellent." We averaged scale items to create a composite score for life satisfaction $(\alpha=0.90)$.

\section{Control Variables}

Following existing studies, age, gender, education, income, and job tenure were included as control variables. $^{70-72}$

We created the Chinese versions of all measures by following commonly used translation/back translation procedures. $^{73}$ The measures were first translated from English to Chinese by a bilingual, native-born Chinese, and then translated back to English by another native-born bilingual speaker who was not familiar with the original 
version of the measures. Discrepancies between the original and the back-translated versions were discussed and resolved by joint agreement of the translators.

\section{Results}

\section{Correlations Among Study Variables}

Table 1 presents the descriptive statistics and bivariate correlations among the different variables. In line with our hypotheses, impression management was negatively associated with life satisfaction $(r=-0.13, p<0.05)$ and sense of control $(r=-0.32, p<0.01)$; whereas it was positively associated with loneliness $(r=0.26, p<0.01)$. Life satisfaction was positively associated with sense of control $(r=0.40, p<0.01)$ and negatively associated with loneliness $(r=-0.46, p<0.01)$.

\section{Measurement Model}

Because the scales of the constructs contained many items, all items for assessing the study variables were aggregated into parcels by following the parceling procedure that averaged lower loaded items with higher loaded ones, and thus minimized the loading differences among the manifest variables. ${ }^{74}$ In the case of multidimensional scales (i.e., loneliness and sense of control), we created one parcel for each dimension. The number of indicators was thereby reduced to 15 : impression management and sense of control had four indicators each; while loneliness had five indicators; and life satisfaction had two indicators.

Because several constructs in our study were conceptually related, we used LISREL8.8 to perform a series of CFAs to verify their distinctiveness. Four indicators of fit were used to assess the models we tested, including chisquare-degrees of freedom ratio $\left(\chi^{2} / d f\right)$, comparative fit index (CFI) ${ }^{75}$ non-normed fit index $(\mathrm{NNFI}),{ }^{76}$ and root mean square error of approximation (RMSEA). ${ }^{77}$ A value of 3 or less for $\chi^{2} / d f$ indicates acceptable fit. ${ }^{78}$ A value of CFI and NNFI in the upper 0.90 s indicates good fit; ${ }^{76}$ whereas the value of RMSEA represents discrepancy, so it is in inverse proportion to the model fit. As suggested by Browne and Cudeck, ${ }^{77} 0.08$ suggests a reasonable fit of the model to the data.

Table 2 presents the results. As shown, the baseline four-factor model yielded the best fit indexes $\left(\chi^{2}=216.70\right.$; $d f=84$; CFI $=0.96$; NNFI $=0.96$; RMSEA $=0.07)$. We also tested five alternative models: Model 1 was a threefactor model with impression management merged with sense of control to form a single factor; Model 2 was another three-factor model with impression management merged with loneliness to form a single factor. Models 3 and 4 were two distinct three-factor models in which sense of control and loneliness, and sense of control and life satisfaction were combined into one factor. In Model 5, loneliness and life satisfaction were combined into one factor. These alternative models exhibited a significantly poorer fit than the baseline model, thus providing clear evidence of the construct's distinctiveness.

\section{Structural Model}

To test our hypotheses, we used SEM methods and compared the hypothetical model with the competing ones. Our baseline model included the paths from impression management to life satisfaction, sense of control, and loneliness, as well as paths from sense of control and loneliness to life satisfaction. In contrast, we omitted the path from impression management to loneliness and the path from loneliness to life satisfaction in Model 2. In Model 3, the indirect effect of impression

Table I Means, Standard Deviations, and Correlations Among All Variables ${ }^{\mathrm{a}}$

\begin{tabular}{|c|c|c|c|c|c|c|c|c|c|c|c|}
\hline & Mean & S.D. & $\mathbf{I}$ & 2 & 3 & 4 & 5 & 6 & 7 & 8 & 9 \\
\hline I. Impression management & 1.51 & 0.25 & $(0.76)$ & & & & & & & & \\
\hline 2. Sense of control & 4.61 & 0.97 & $-0.32 * *$ & $(0.82)$ & & & & & & & \\
\hline 3. Loneliness & 2.72 & 0.86 & $0.26 * *$ & $-0.43 * *$ & $(0.89)$ & & & & & & \\
\hline 4. Life satisfaction & 3.81 & 1.21 & $-0.13 *$ & $0.40^{* *}$ & $-0.46 * *$ & $(0.90)$ & & & & & \\
\hline 5. Gender & 1.62 & 0.49 & $-0.14 *$ & $0.15^{*}$ & $-0.24 * *$ & $0.14 *$ & & & & & \\
\hline 6. Age & 2.21 & 0.41 & -0.11 & 0.08 & -0.00 & 0.07 & -0.01 & & & & \\
\hline 7. Income & 2.68 & 0.85 & -0.11 & 0.09 & 0.07 & 0.10 & $-0.14 *$ & $0.29 * *$ & & & \\
\hline 8. Education & 3.33 & 0.52 & -0.02 & 0.07 & -0.07 & 0.05 & -0.02 & -0.11 & 0.06 & & \\
\hline 9. Job tenure & 2.66 & 0.75 & -0.01 & 0.08 & 0.07 & -0.03 & -0.08 & $0.23 * *$ & 0.00 & $0.25 * *$ & \\
\hline
\end{tabular}

Notes: $\mathrm{N}=243$. Gender: I = male; 2 = female. Age: $I=$ less than 18 years old; $2=18-35$ years old; $3=36-53$ years old; $4=$ more than 54 years old. Income: $I=$ less than 2000 yuan; $2=2000-4000$ yuan; $3=400 \mathrm{I}-6000$ yuan; $4=$ more than 6000 yuan. Education: $I=$ high school; $2=$ some college; $3=$ bachelor's degree; $4=$ master's degree or higher. Job tenure: $\mathrm{I}=$ less than I year; $2=2-3$ years; $3=4-5$ years; $4=$ more than 6 years. $* p<0.05$. ${ }^{* *} p<0.0 \mathrm{I}$. ${ }^{\mathrm{a}}$ Internal consistency reliabilities are on the diagonal, in parentheses. 
Table 2 Comparison of Measurement Models for Main Variables in the Study

\begin{tabular}{|l|l|l|l|l|l|l|l|}
\hline Model & Factors & $d f$ & $\chi^{2}$ & $\Delta \chi^{2}$ & CFI & NNFI & RMSEA \\
\hline Baseline model & Four factors & 84 & 216.70 & - & 0.96 & 0.96 & 0.07 \\
Model I & $\begin{array}{l}\text { Three factors: impression management and sense of control were } \\
\text { combined into one factor. }\end{array}$ & 87 & 614.02 & $397.32 * *$ & 0.86 & 0.83 & 0.14 \\
Model 2 & $\begin{array}{l}\text { Three factors: impression management and loneliness were combined } \\
\text { into one factor. }\end{array}$ & 87 & 597.89 & $381.19 * *$ & 0.86 & 0.83 & 0.15 \\
Model 3 & $\begin{array}{l}\text { Three factors: sense of control and loneliness were combined into one } \\
\text { factor. }\end{array}$ & 87 & 1076.55 & $859.85 * *$ & 0.74 & 0.68 & 0.19 \\
Model 4 & $\begin{array}{l}\text { Three factors: sense of control and life satisfaction were combined } \\
\text { into one factor. }\end{array}$ & 87 & 570.91 & $354.21 * *$ & 0.87 & 0.85 & 0.13 \\
& $\begin{array}{l}\text { Three factors: loneliness and life satisfaction were combined into one } \\
\text { factor. }\end{array}$ & 87 & 525.45 & $308.75 * *$ & 0.88 & 0.86 & 0.13 \\
\hline
\end{tabular}

Notes: $\mathrm{N}=243$. ${ }^{* *} p<0.01$.

Abbreviations: CFI, comparative fit index; NNFI, non-normed fit index; RMSEA, root mean square error of approximation.

management on life satisfaction through sense of control was cut out. Model 4 depicted that impression management only had main effect on life satisfaction. We included all the control variables in these four models, and summarized the results in Table 3. It reveals that the baseline model fitted the data well $\left(\chi^{2}=415.67, d f=155 ; \mathrm{CFI}=0.94, \mathrm{NNFI}=0.93, \mathrm{RMSEA}=\right.$ 0.07 ); whereas models $2-4$ exhibited a significantly poorer fit compared with the baseline one, manifested by the significant chi-square difference tests (Model 2: $\Delta \chi^{2}(2)=32.58, p<0.01$; Model 3: $\Delta \chi^{2}(2)=13.16, p<0.01$; Model 4: $\Delta \chi^{2}(1)=32.58$, $p<0.01)$ and model fit indexes.

Figure 1 displays the standardized path coefficients of the baseline model. Impression management did not significantly relate to life satisfaction $(\beta=-0.01, p>0.90)$. However, the path coefficients between impression management and sense of control $(\beta=-0.29, p<0.01)$ and loneliness $(\beta=0.34, p<0.01)$ were both significant, supporting Hypothesis $2 \mathrm{a}$ and $2 \mathrm{~b}$, respectively. Moreover, paths to life satisfaction from sense of control $(\beta=0.17$, $p<0.05)$ and loneliness $(\beta=-0.39, p<0.01)$ were both significant in the predicted directions. Because the mediating effect of sense of control and loneliness received evidence, Hypothesis $3 \mathrm{a}$ and $3 \mathrm{~b}$ were supported.
To further test the mediation hypotheses, we used bootstrapping procedures that generated a sample size of $5000 .^{79}$ As illustrated in Table 4, the indirect effects of impression management on life satisfaction through sense of control and loneliness were both significant, because their 95\% confidence intervals both excluded zero. Similarly, the direct effects of impression management on sense of control and loneliness, the direct effect of sense of control on life satisfaction, and the direct effect of loneliness on life satisfaction were all significant. Taken together, the data supported our hypotheses.

\section{Discussion}

The present research examines the influence of impression management on people's satisfaction with life. It also reveals that sense of control and loneliness mediate this relationship. The empirical results from original survey data supported our hypotheses. Specifically, the correlational analyses found that impression management was negatively related to life satisfaction and sense of control; whereas it was positively associated with loneliness. In addition, sense of control and loneliness was positively and negatively related to life satisfaction, respectively.

Table 3 Comparisons of Structural Equation Models

\begin{tabular}{|l|l|l|l|l|l|l|}
\hline Model Specifications & df & $\chi^{2}$ & $\Delta \chi^{2}$ & CFI & NNFI & RMSEA \\
\hline I. IM $\rightarrow$ SOC+Loneliness $\rightarrow$ LS $^{\text {a }}$ & 155 & 415.67 & - & 0.94 & 0.93 & 0.07 \\
2. IM $\rightarrow$ SOC $\rightarrow$ LS & 157 & 448.25 & $32.58^{* *}$ & 0.92 & 0.91 & 0.07 \\
3. IM $\rightarrow$ Loneliness $\rightarrow$ LS & 157 & 428.83 & $13.16^{* *}$ & 0.93 & 0.91 & 0.07 \\
4. IM $\rightarrow$ LS & 156 & 442.16 & $26.49 * *$ & 0.93 & 0.91 & 0.08 \\
\hline
\end{tabular}

Notes: $\mathrm{N}=243 . \Delta \chi^{2}$ is the change of $\chi^{2}$ compared with the baseline model. ${ }^{*} p<0.01$. 'Baseline model.

Abbreviations: IM, impression management; SOC, sense of control; LS, life satisfaction; CFI, comparative fit index; NNFI, non-normed fit index; RMSEA, root mean square error of approximation. 


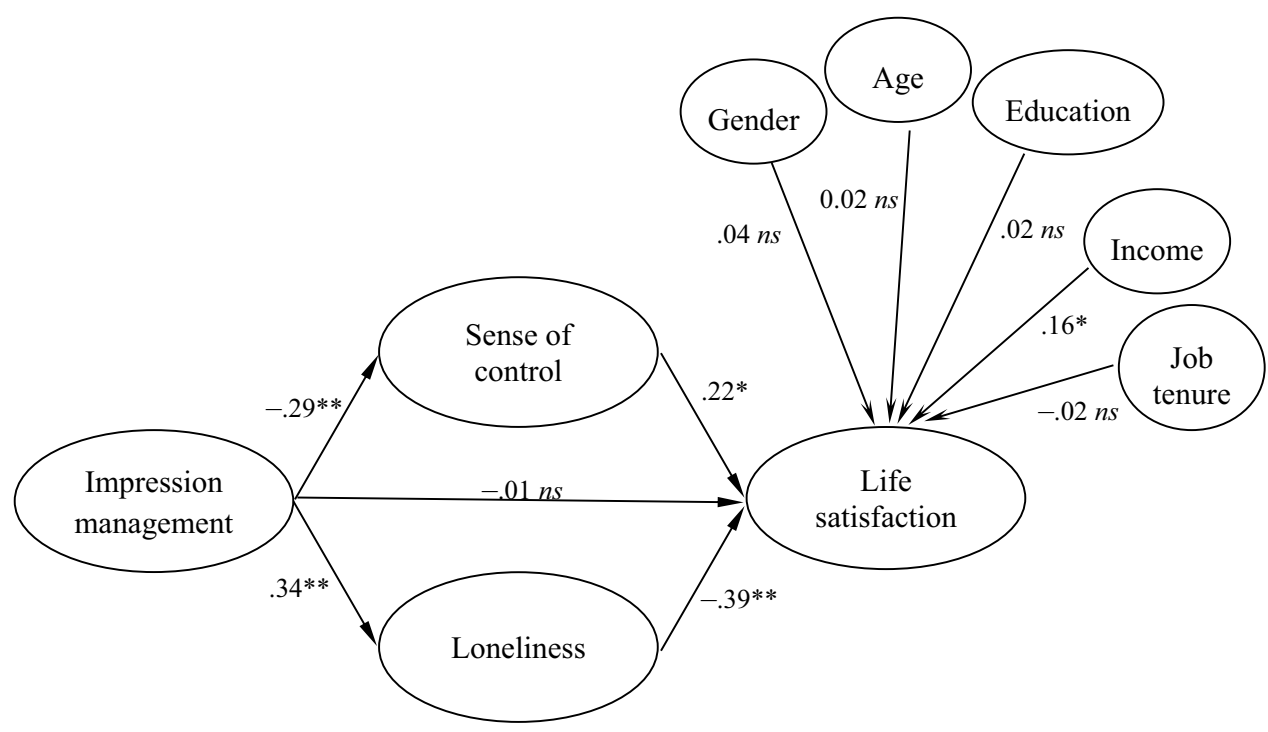

Figure I Path coefficients of the hypothesized model.

Notes: $N=243$. Standardized path coefficients are reported here. ${ }^{*} p<0.05$. ${ }^{*} p p<0.01$. This figure displays the standardized path coefficients of the research model. The main and control variables are all included.

We obtained further support from SEM results: the full mediation model indicated that impression management affected sense of control and loneliness, which in turn influenced life satisfaction. Finally, the mediation received robust and convergent evidence form the bootstrapping analyses.

This paper contributes to the literature in three ways. First, though mixed and indirect support for how impression management affects life satisfaction is available, ${ }^{11,14}$ there is presently little research examining the impact of impression management on life satisfaction. Our research fills this gap

Table 4 Direct and Indirect Effects and 95\% Confidence Intervals

\begin{tabular}{|l|l|l|}
\hline & $\begin{array}{l}\text { Estimated } \\
\text { Effect }\end{array}$ & $95 \%$ CI \\
\hline $\begin{array}{l}\text { Direct Effects } \\
\text { Impression management } \rightarrow \text { sense } \\
\text { of control } \\
\text { Impression management } \rightarrow \\
\text { loneliness } \\
\text { Sense of control } \rightarrow \text { life } \\
\text { satisfaction } \\
\text { Loneliness } \rightarrow \text { life satisfaction }\end{array}$ & $-0.91^{* *}$ & {$[-1.31,-0.52]$} \\
\hline $\begin{array}{l}\text { Indirect Effects } \\
\text { Impression management } \rightarrow \text { sense } \\
\text { of control } \rightarrow \text { life satisfaction } \\
\text { Impression management } \rightarrow \\
\text { loneliness } \rightarrow \text { life satisfaction }\end{array}$ & $-0.27^{* *}$ & {$[0.61,1.32]$} \\
\hline
\end{tabular}

Notes: $\mathrm{N}=243 .{ }^{*} \mathrm{p}<0.01$.

Abbreviation: $\mathrm{Cl}$, confidence interval. by showing that impression management is associated with lower life satisfaction. This finding makes a significant contribution to the impression management and life satisfaction literature by revealing the well-being lost due to impression management. Second, we empirically demonstrate that the effect of impression management on life satisfaction takes place through sense of control. So we add to the literature documenting the antecedents and consequences of sense of control. $^{80,81}$ Third, loneliness is regarded as the passive influence of social events, such as social exclusion. ${ }^{54}$ But we propose that impression management, as a proactive behavior, can also make one lonely. Thus we contribute to the loneliness literature by bridging impression management and loneliness.

Living a good life is important for most individuals. ${ }^{82,83}$ Therefore, our research has several practical implications. Although some previous studies show that impression management positively contributes to self-esteem ${ }^{1}$ and desired identities, ${ }^{1,84}$ our research reveals the possible dark side of impression management. Our findings are consistent with a larger body of research indicating that a good impression manager does not necessarily have a good life. For example, research has shown that impression management may increase fear and pressure, ${ }^{25,26}$ while decreasing physical and mental health levels. ${ }^{26,31-33}$ Impression management is a common action for many people. Based on our results, one should realize that impression management has not only positive effects, but also negative impacts. In addition, we also note that impression management impedes life 
satisfaction through increasing the loss of sense of control and loneliness. Thus, if impression management is inevitable in certain social contexts, individuals may prevent their life satisfaction from decreasing by building new social relationships and participating in social activities to avoid feeling lonely, or by gaining status and reducing uncertainty to enhance sense of control.

\section{Limitations and Future Directions}

This study has three limitations that point to research directions in the future. First, the research was conducted in China, whose collectivism values are quite different from the individualism values in the West. ${ }^{85}$ The cultural discrepancies may result in different orientations of impression management. According to Zaidman and Drory, ${ }^{86}$ impression managers in western countries are more prone to building competent self-images. Impression managers in the East, however, focus more on pleasing others except for showing competence, which has been shown to negatively affect subjective well-being. ${ }^{87}$ Meanwhile, we found that the sample in the current research is young and well educated. Future research can further validate our findings by using a more general sample. Second, the cross-sectional design of this study only allows for correlational rather than causal inferences. ${ }^{88,89}$ Future research may further strengthen the causal inferences by adopting longitudinal or experimental designs. Finally, we did not investigate the boundary conditions of the effect. It is possible that impression management no longer decreases life satisfaction under some circumstances. For example, since powerful individuals have not only tangible control over others and resources, ${ }^{90,91}$ but also better social connections and relationships, ${ }^{92}$ the mechanism through which impression management negatively influences life satisfaction is disrupted. Consequently, it is entirely possible for holders of power to maintain a good life even if they frequently engage in impression management. Another possible boundary condition is whether the impression management work meets others' evaluative standards (i.e., the results of impression management). Successful impression management enhances one's social image, which can lead to higher sense of control and therefore positively contributes to wellbeing.

\section{Conclusions}

In conclusion, this research investigates how impression management influences life satisfaction. Specifically, the results show that impression management is negatively related to life satisfaction, and sense of control and loneliness fully mediate this effect. These results identify impression management as an indicator of life satisfaction, and illustrate the underlying mechanism of this relationship, and are theoretically important and practically useful.

\section{Disclosure}

The authors report no conflicts of interest in this work.

\section{References}

1. Leary MR, Kowalski RM. Impression management: a literature review and two-component model. Psychol Bull. 1990;107(1):34. doi:10.1037/0033-2909.107.1.34

2. Zettler I, Hilbig BE, Moshagen M, de Vries RE. Dishonest responding or true virtue? A behavioral test of impression management. Pers Individ Dif. 2015;81:107-111. doi:10.1016/j.paid.2014.10.007

3. Tetlock PE, Manstead AS. Impression management versus intrapsychic explanations in social psychology: a useful dichotomy? Psychol Rev. 1985;92(1):59. doi:10.1037/0033-295x.92.1.59

4. Schlosser AE. The effect of computer-mediated communication on conformity vs. nonconformity: an impression management perspective. J Consum Psychol. 2009;19(3):374-388. doi:10.1016/j. jeps.2009.03.005

5. Wayne SJ, Kacmar KM. The effects of impression management on the performance appraisal process. Organ Behav Hum Decis Process. 1991;48(1):70-88. doi:10.1016/0749-5978(91)90006-f

6. Fenigstein A. Self-consciousness, self-attention, and social interaction. J Pers Soc Psychol. 1979;37(1):75. doi:10.1037/00223514.37.1.75

7. Morrison EW, Bies RJ. Impression management in the feedback-seeking process: a literaturereview and research agenda. Acad Manage Rev. 1991;16(3):522-541. doi:10.5465/amr.1991.42 79472

8. Deluga RJ. The relationship of upward-influencing behavior with subordinate-impression management characteristics 1. J Appl Soc Psychol. 1991;21(14):1145-1160. doi:10.1111/j.1559-1816.1991.tb0 0463.x

9. Rudman LA. Self-promotion as a risk factor for women: the costs and benefits of counterstereotypical impression management. J Pers Soc Psychol. 1998;74(3):629. doi:10.1037/0022-3514.74.3.629

10. Turnley WH, Bolino MC. Achieving desired images while avoiding undesired images: exploring the role of self-monitoring in impression management. J Appl Psychol. 2001;86(2):351. doi:10.1037/00219010.86.2.351

11. Ashworth L, Darke PR, Schaller M. No one wants to look cheap: trade-offs between social disincentives and the economic and psychological incentives to redeem coupons. J Consum Psychol. 2005;15 (4):295-306. doi:10.1207/s15327663jcp1504_4

12. Chen S, Shechter D, Chaiken S. Getting at the truth or getting along: accuracy-versus impression-motivated heuristic and systematic processing. J Pers Soc Psychol. 1996;71(2):262. doi:10.1037//00223514.71.2.262

13. Jain AK. Does emotional intelligence predict impression management? J Organ Cult Commun Confl. 2012;16(2):1. doi:10.19 070/2332-3000-1500014

14. Bolino M, Long D, Turnley W. Impression management in organizations: critical questions, answers, and areas for future research. Annu Rev Organ Psychol Organ Behav. 2016;3:377-406. doi:10.1146/ annurev-orgpsych-041015-062337 
15. Jones EE, Pittman TS. Toward a general theory of strategic self-presentation. Psychol Perspect Self. 1982;1(1):231-262.

16. Diener ED, Emmons RA, Larsen RJ, Griffin S. The satisfaction with life scale. J Pers Assess. 1985;49(1):71-75. doi:10.1207/s15327 752jpa4901_13

17. Berinsky AJ. Can we talk? Self-presentation and the survey response. Polit Psychol. 2004;25(4):643-659. doi:10.1111/j.1467-9221.2004 00391.x

18. Alexander CN Jr, Knight GW. Situated identities and social psychological experimentation. Sociometry. 1971;65-82. doi:10.2307/ 2786351

19. Rosenfeld P, Giacalone RA, Riordan CA. Impression Management in Organizations: Theory, Measurement, Practice. Van Nostrand Reinhold; 1995.

20. Krämer NC, Winter S. Impression management 2.0: the relationship of self-esteem, extraversion, self-efficacy, and self-presentation within social networking sites. J Media Psychol. 2008;20(3):10 6-116. doi:10.1027/1864-1105.20.3.106

21. Blair S, Roese NJ. Balancing the basket: the role of shopping basket composition in embarrassment. J Consum Res. 2013;40(4):676-691. doi:10.1086/671761

22. Liu D, Wang S, Wayne SJ. Is being a good learner enough? An examination of the interplay between learning goal orientation and impression management tactics on creativity. Pers Psychol. 2015;68 (1):109-142. doi:10.1111/peps. 12064

23. Harris KJ, Kacmar KM, Zivnuska S, Shaw JD. The impact of political skill on impression management effectiveness. $J$ Appl Psychol. 2007;92(1):278. doi:10.1037/0021-9010.92.1.278

24. Bono JE, Judge TA. Core self-evaluations: a review of the trait and its role in job satisfaction and job performance. Eur J Pers. 2003;17 (S1):S5-S18. doi:10.1002/per.481

25. Christopher AN, Schlenker BR. Materialism and affect: the role of self-presentational concerns. J Soc Clin Psychol. 2004;23(2):26 0-272. doi:10.1521/jscp.23.2.260.31022

26. Leary MR, Tchividijian LR, Kraxberger BE. Self-presentation can be hazardous to your health: impression management and health risk Health Psychol. 1994;13(6):461. doi:10.1037/0278-6133.13.6.461

27. Benthaus J, Risius M, Beck R. Social media management strategies for organizational impression management and their effect on public perception. J Strateg Inf Syst. 2016;25(2):127-139. doi:10.1016/j. jsis.2015.12.001

28. Pounders K, Kowalczyk CM, Stowers K. Insight into the motivation of selfie postings: impression management and self-esteem. Eur $J$ Mark. 2016;50:1879-1892. doi:10.1108/EJM-07-2015-0502

29. Siibak A. Constructing the self through the photo selection-visual impression management on social networking websites. Cyberpsychology J Psychosoc Res Cybersp. 2009;3(1).

30. Ranzini G, Hoek E. To you who (I think) are listening: imaginary audience and impression management on facebook. Comput Human Behav. 2017;75:228-235. doi:10.1016/j.chb.2017.04.047

31. Jang K, Park N, Song H. Social comparison on facebook: its antecedents and psychological outcomes. Comput Human Behav. 2016;62:147-154. doi:10.1016/j.chb.2016.03.082

32. Kelly Y, Zilanawala A, Booker C, et al. Social media use and adolescent mental health: findings from the UK millennium cohort study. E Clin Med. 2018;6:59-68. doi:10.1016/j.eclinm.2018.12.005

33. Berryman C, Ferguson CJ, Negy C. Social media use and mental health among young adults. Psychiatr Q. 2018;89(2):307-314. doi:10.1007/s11126-017-9535-6

34. Yucel D, Minnotte KL. Workplace support and life satisfaction: the mediating roles of work-to-family conflict and mental health. Appl Res Qual Life. 2017;12(3):549-575. doi:10.1007/s11482-016-9476-5

35. Lachman ME, Neupert SD, Agrigoroaei S. The relevance of control beliefs for health and aging In: Schaie $\mathrm{KW} \&$ Willis SL, editors. Handbook of the Psychology of Aging. San Diego: Academic Press; 2011:175-190.
36. Dubois N. The norm of internality: social valorization of internal explanations of behavior and reinforcements in young people. $J$ Soc Psychol. 1988;128(4):431-439. doi:10.1080/00224545.1988.9713763

37. Millham J, Kellogg RW. Need for social approval: impression management or self-deception? J Res Pers. 1980;14(4):445-457. doi:10.1016/0092-6566(80)90003-3

38. Ingold PV, Kleinmann M, König CJ, et al. Shall we continue or stop disapproving of self-presentation? Evidence on impression management and faking in a selection context and their relation to job performance. Eur J Work Organ Psychol. 2015;24(3):420-432. doi:10.1080/1359432X.2014.915215

39. Weiss B, Feldman RS. Looking good and lying to do it: deception as an impression management strategy in job interviews. J Appl Soc Psychol. 2006;36(4):1070-1086. doi:10.1111/j.0021-9029.2006.00055.x

40. Eichhorn KC. Soliciting and providing social support over the Internet: an investigation of online eating disorder support groups. J Comput Commun. 2008;14(1):67-78. doi:10.1111/j.1083-6101.20 08.01431.x

41. Shumaker SA, Brownell A. Toward a theory of social support: closing conceptual gaps. J Soc Issues. 1984;40(4):11-36. doi:10.1111/ j.1540-4560.1984.tb01105.x

42. McGuire AP, Gauthier JM, Anderson LM, et al. Social support moderates effects of natural disaster exposure on depression and posttraumatic stress disorder symptoms: effects for displaced and nondisplaced residents. J Trauma Stress. 2018;31(2):223-233. doi:10.1002/jts.22270

43. Shang F, Kaniasty K, Cowlishaw S, et al. Social support following a natural disaster: a longitudinal study of survivors of the 2013 Lushan earthquake in China. Psychiatry Res. 2019;273:641-646. doi:10.1016/j.psychres.2019.01.085

44. Connolly-Ahern C, Broadway SC. The importance of appearing competent: an analysis of corporate impression management strategies on the World Wide Web. Public Relat Rev. 2007;33(3):343-345. doi:10.1016/j.pubrev.2007.05.017

45. Hombrados-Mendieta I, García-Martín MA, Gómez-Jacinto L. The relationship between social support, loneliness, and subjective well-being in a Spanish sample from a multidimensional perspective. Soc Indic Res. 2013;114(3):1013-1034. doi:10.1007/ s11205-012-0187-5

46. Zhao J, Song F, Chen Q, et al. Linking shyness to loneliness in Chinese adolescents: the mediating role of core self-evaluation and social support. Pers Individ Dif. 2018;125:140-144. doi:10.1016/j. paid.2018.01.007

47. Zhang S, Tian Y, Sui Y, et al. Relationships between social support, loneliness, and internet addiction in Chinese postsecondary students: a longitudinal cross-lagged analysis. Front Psychol. 2018;9:1707. doi:10.3389/fpsyg.2018.01707

48. Lachman ME, Weaver SL. The sense of control as a moderator of social class differences in health and well-being. J Pers Soc Psychol. 1998;74(3):763. doi:10.1037/0022-3514.74.3.763

49. Inesi ME, Botti S, Dubois D, Rucker DD, Galinsky AD. Power and choice: their dynamic interplay in quenching the thirst for personal control. Psychol Sci. 2011;22(8):1042-1048. doi:10.1177/095679 7611413936

50. Lachman ME. Perceived control over aging-related declines: adaptive beliefs and behaviors. Curr Dir Psychol Sci. 2006;15(6):282-286. doi:10.1111/j.1467-8721.2006.00453.x

51. Larson R. Is feeling "in control" related to happiness in daily life? Psychol Rep. 1989;64(3):775-784. doi:10.2466/pr0.1989.64.3.775

52. Russell D, Cutrona CE, Rose J, Yurko K. Social and emotional loneliness: an examination of weiss's typology of loneliness. J Pers Soc Psychol. 1984;46(6):1313. doi:10.1037/0022-3514.46.6.1313

53. Zhou X, Sedikides C, Wildschut T, Gao DG. Counteracting loneliness: on the restorative function of nostalgia. Psychol Sci. 2008;19 (10):1023-1029. doi:10.1111/j.1467-9280.2008.02194.x 
54. Twenge JM, Catanese KR, Baumeister RF. Social exclusion and the deconstructed state: time perception, meaninglessness, lethargy, lack of emotion, and self-awareness. J Pers Soc Psychol. 2003;85(3):409. doi:10.1037/0022-3514.85.3.409

55. Molden DC, Lucas GM, Gardner WL, Dean K, Knowles ML. Motivations for prevention or promotion following social exclusion: being rejected versus being ignored. J Pers Soc Psychol. 2009;96 (2):415. doi:10.1037/a0012958

56. Fontaine RG, Yang C, Burks VS, et al. Loneliness as a partial mediator of the relation between low social preference in childhood and anxious/depressed symptoms in adolescence. Dev Psychopathol. 2009;21(2):479-491. doi:10.1017/s0954579409000261

57. Kapıkıran Ş. Loneliness and life satisfaction in Turkish early adolescents: the mediating role of self esteem and social support. Soc Indic Res. 2013;111(2):617-632. doi:10.1007/s11205-012-0024-x

58. Jones WH, Hobbs SA, Hockenbury D. Loneliness and social skill deficits. J Pers Soc Psychol. 1982;42(4):682. doi:10.1037/0022-3514. 42.4.682

59. Solano $\mathrm{CH}$, Batten PG, Parish EA. Loneliness and patterns of self-disclosure. J Pers Soc Psychol. 1982;43(3):524. doi:10.1037/ 0022-3514.43.3.524

60. Sinha J, Wang J. How time horizon perceptions and relationship deficits affect impulsive consumption. J Mark Res. 2013;50 (5):590-605. doi:10.1509/jmr.11.0246

61. Twenge JM, Baumeister RF, DeWall CN, Ciarocco NJ, Bartels JM. Social exclusion decreases prosocial behavior. J Pers Soc Psychol. 2007;92(1):56. doi:10.1037/0022-3514.92.1.56

62. Twenge JM, Catanese KR, Baumeister RF. Social exclusion causes self-defeating behavior. J Pers Soc Psychol. 2002;83(3):606. doi:10.1037/0022-3514.83.3.606

63. Feng M, Xiong X, Li J. Spiritual intelligence scale-Chinese form: construction and initial validation. Curr Psychol. 2019;38(5):13 18-1327. doi:10.1007/s12144-017-9678-5

64. Zhang M. The bright side of stressed frontline employees in service recovery: the combination causes of organizational empowerment and self-regulation processes. Psychol Res Behav Manag. 2019;12: 1087. doi:10.2147/PRBM.S228902

65. Reynolds WM. Development of reliable and valid short forms of the Marlowe-Crowne social desirability scale. J Clin Psychol. 1982;38 (1):119-125. doi:10.1002/1097-4679(198201)38:1\%3C119::aid-jclp22 70380118\%3E3.0.co;2-I

66. Hunsley J, Vito D, Pinsent C, James S, Lefebvre M. Are self-report measures of dyadic relationships influenced by impression management biases? J Fam Psychol. 1996;10(3):322. doi:10.1037/08933200.10.3.322

67. Uziel L. Rethinking social desirability scales: from impression management to interpersonally oriented self-control. Perspect Psychol Sci. 2010;5(3):243-262. doi:10.1177/1745691610369465

68. Loo R, Thorpe K. Confirmatory factor analyses of the full and short versions of the Marlowe-Crowne social desirability scale. J Soc Psychol. 2000;140(5):628-635. doi:10.1080/00224540009600503

69. Russell DW. UCLA loneliness scale (Version 3): reliability, validity, and factor structure. J Pers Assess. 1996;66(1):20-40. doi:10.1207/ s15327752jpa6601_2

70. Howell RT, Howell CJ. The relation of economic status to subjective well-being in developing countries: a meta-analysis. Psychol Bull. 2008;134(4):536. doi:10.1037/0033-2909.134.4.536

71. Judge TA, Watanabe S. Another look at the job satisfaction-life satisfaction relationship. $J$ Appl Psychol. 1993;78(6):939. doi:10.10 37/0021-9010.78.6.939

72. Oishi S, Diener E, Lucas RE, Suh EM. Cross-cultural variations in predictors of life satisfaction: Perspectives from needs and values. In: Diener E, editors, Culture and Well-Being. Dordrecht: Springer; 2009:109-127.
73. Brislin RW. Translation and content analysis of oral and written materials. Methodology. 1980:389-444.

74. Little TD, Cunningham WA, Shahar G, Widaman KF. To parcel or not to parcel: exploring the question, weighing the merits. Struct Equ Model. 2002;9(2):151-173. doi:10.1207/s15328007sem0902_1

75. Bentler PM. Comparative fit indexes in structural models. Psychol Bull. 1990;107(2):238. doi:10.1037/0033-2909.107.2.238

76. Bentler PM, Bonett DG. Significance tests and goodness of fit in the analysis of covariance structures. Psychol Bull. 1980;88(3):588. doi:10.1037/0033-2909.88.3.588

77. Browne MW, Cudeck R. Alternative ways of assessing model fit. Sage Focus Ed. 1993;154:136.

78. Hinkin TR. A brief tutorial on the development of measures for use in survey questionnaires. Organ Res Methods. 1998;1(1):104-121. doi:10.1177/109442819800100106

79. Hayes AF. Introduction to Mediation, Moderation, and Conditional Process Analysis: A Regression-Based Approach. Guilford Publications; 2017.

80. Infurna FJ, Gerstorf D, Ram N, Schupp J, Wagner GG. Long-term antecedents and outcomes of perceived control. Psychol Aging. 2011;6(3):559. doi:10.1037/a0022890

81. Kouchaki M, Oveis C, Gino F. Guilt enhances the sense of control and drives risky judgments. J Exp Psychol Gen. 2014;143(6):2103. doi:10.1037/a0037932

82. Abbott P, Wallace C, Lin K, Haerpfer C. The quality of society and life satisfaction in China. Soc Indic Res. 2016;127(2):653-670. doi:10.1007/s11205-015-0989-3

83. Cikrikci Ö, Odaci H. The determinants of life satisfaction among adolescents: the role of metacognitive awareness and self-efficacy. Soc Indic Res. 2016;125(3):977-990. doi:10.1007/s11205-015-0861-5

84. Rosenberg M. Conceiving the Self. New York (NY): Basic Books; 1979.

85. Cheung FM, Leung K, Zhang JX, et al. Indigenous Chinese personality constructs: is the five-factor model complete? J Cross Cult Psychol. 2001;32(4):407-433. doi:10.1177/0022022101032004003

86. Zaidman N, Drory A. Upward impression management in the work place cross-cultural analysis. Int $J$ Intercult Relat. 2001;25 (6):671-690. doi:10.1016/S0147-1767(01)00031-1

87. Goldman BM, Kernis MH. The role of authenticity in healthy psychological functioning and subjective well-being. Ann Am Psychother Assoc. 2002;5(6):18-20.

88. Knemeyer AM, Naylor RW. Using behavioral experiments to expand our horizons and deepen our understanding of logistics and supply chain decision making. J Bus Logist. 2011;32(4):296-302. doi:10.1111/j.0000-0000.2011.01025.x

89. Newcomb MD, Felix-Ortiz M. Multiple protective and risk factors for drug use and abuse: cross-sectional and prospective findings. J Pers Soc Psychol. 1992;63(2):280. doi:10.1037/0022-3514.63.2. 280

90. Guinote A, Cotzia I, Sandhu S, Siwa P. Social status modulates prosocial behavior and egalitarianism in preschool children and adults. Proc Natl Acad Sci. 2015;112(3):731-736. doi:10.1073/ pnas. 1414550112

91. Jouffre S. Power modulates over-reliance on false cardiac arousal when judging target attractiveness: the powerful are more centered on their own false arousal than the powerless. Pers Soc Psychol Bull. 2015;41(1):116-126. doi:10.1177/0146167214559718

92. Waytz A, Chou EY, Magee JC, Galinsky AD. Not so lonely at the top: the relationship between power and loneliness. Organ Behav Hum Decis Process. 2015;130:69-78. doi:10.1016/j.obhdp.2015.06. 002 


\section{Publish your work in this journal}

Psychology Research and Behavior Management is an international, peer-reviewed, open access journal focusing on the science of psychology and its application in behavior management to develop improved outcomes in the clinical, educational, sports and business arenas. Specific topics covered in the journal include: Neuroscience, memory and decision making; Behavior modification and management; Clinica

applications; Business and sports performance management; Social and developmental studies; Animal studies. The manuscript management system is completely online and includes a very quick and fair peer-review system, which is all easy to use. Visit http://www. dovepress.com/testimonials.php to read real quotes from published authors. 